\title{
Coupling WRF Double-Moment 6-Class Microphysics Schemes to RRTMG Radiation Scheme in Weather Research Forecasting Model
}

\author{
Soo Ya Bae, ${ }^{1}$ Song-You Hong, ${ }^{1}$ and Kyo-Sun Sunny Lim ${ }^{2}$ \\ ${ }^{1}$ Korea Institute of Atmospheric Prediction Systems (KIAPS), 35 Boramae-ro 5-gil, Dongjak-gu, Seoul 70770, Republic of Korea \\ ${ }^{2}$ Atmospheric Sciences and Global Change Division, Pacific Northwest National Laboratory, Richland, WA 99354, USA \\ Correspondence should be addressed to Soo Ya Bae; sy.bae@kiaps.org
}

Received 22 December 2015; Revised 5 April 2016; Accepted 13 April 2016

Academic Editor: Mario M. Miglietta

Copyright (C) 2016 Soo Ya Bae et al. This is an open access article distributed under the Creative Commons Attribution License, which permits unrestricted use, distribution, and reproduction in any medium, provided the original work is properly cited.

A method to explicitly calculate the effective radius of hydrometeors in the Weather Research Forecasting (WRF) double-moment 6-class (WDM6) microphysics scheme is designed to tackle the physical inconsistency in cloud properties between the microphysics and radiation processes. At each model time step, the calculated effective radii of hydrometeors from the WDM6 scheme are linked to the Rapid Radiative Transfer Model for GCMs (RRTMG) scheme to consider the cloud effects in radiative flux calculation. This coupling effect of cloud properties between the WDM6 and RRTMG algorithms is examined for a heavy rainfall event in Korea during 25-27 July 2011, and it is compared to the results from the control simulation in which the effective radius is prescribed as a constant value. It is found that the derived radii of hydrometeors in the WDM6 scheme are generally larger than the prescribed values in the RRTMG scheme. Consequently, shortwave fluxes reaching the ground (SWDOWN) are increased over less cloudy regions, showing a better agreement with a satellite image. The overall distribution of the 24-hour accumulated rainfall is not affected but its amount is changed. A spurious rainfall peak over the Yellow Sea is alleviated, whereas the local maximum in the central part of the peninsula is increased.

\section{Introduction}

Clouds exert a significant influence on weather and climate by absorbing or reflecting solar radiation [1]. For example, cirrus clouds allow most of the sunlight to reach the surface, whereas thicker cumulus clouds reflect much of the sunlight back into space. Thus, the cloud effects on radiative fluxes are very sensitive to cloud type, which is characterized by the amount, phase, and size of hydrometeors [2]. In particular, the size of hydrometeors comprising clouds is one of the important factors determining cloud optical depths, but it is typically assumed to be a function of temperature and surface type, or it is roughly estimated with a radiation scheme in most models. Recently, researchers tried to study proper coupling of water substances in microphysics and radiation processes. For example, explicit coupling between the Thompson microphysics scheme and the Rapid Radiative Transfer Model for GCMs (RRTMG) radiation scheme for the purpose of calculating cloud optical properties is available in Weather Research Forecasting (WRF) (v3.5.1 and higher) [3]. Thompson et al. [3] showed that radiation fluxes reaching ground with the revised approach are better matched with observations.

An RRTMG radiation scheme [4] is broadly used in weather forecasting models, and it specifies the size of hydrometeors regardless of cloud type or amount for radiation calculations. This scheme utilizes the correlated- $k$ approach to calculate fluxes and the heating rate efficiently and accurately [5], and it includes the Monte-Carlo Independent Column Approximation (McICA) technique $[6,7]$ for representing subgrid cloud variability. The effective radii of cloud droplets are, however, implicitly calculated as a function of temperature, snow depth, and sea ice fraction. For ice particles, a lookup table is used to calculate their radii as a function of atmospheric temperature for the range of $180-274 \mathrm{~K}$ over which the radii vary in the range of $5.928-250.6 \mu \mathrm{m}$ with the 
maximum of $140 \mu \mathrm{m}$ for computing the cloud optical depth with ice particles. The effective radius of the snow is assumed to be constant at $10 \mu \mathrm{m}$.

Calculating the effective radii of hydrometeors consisting of a cloud requires their number and mass concentrations. For this, double-moment bulk microphysical schemes, such as Thompson [8], WRF double-moment 6-class (WDM6) [9], and Morrison [10] schemes, are needed, and they are implemented in the WRF model. For example, the Thompson microphysics scheme predicts the mass mixing ratio and number concentration of cloud ice and rain drops. Snow is unique in this scheme, because its density varies inversely with its diameter. The double-moment method is applied for warm rain microphysics in the WDM6 scheme, which predicts the number concentration of cloud drops and rain drops [9]. The Morrison scheme predicts the mass and number concentration of five hydrometeors: rain, ice, snow, graupel, and hail. There is a user-set switch for the rimed ice category to have properties of graupel or hail consistently [11]. The comparison studies of cloud microphysics schemes showed that the WDM6 simulation resulted in consistent structures and extents of simulated precipitation with observations relative to those of other schemes [1214]. However, the WDM6 scheme does not yet include the computation process for the effective radii of hydrometeors.

The objective of this study is to develop a method for explicitly calculating the size of hydrometeors with the WDM6 microphysics scheme and to achieve physical consistency between the WDM6 microphysics and the RRTMG radiation schemes by using the calculated effective radii of hydrometeors for a radiative flux calculation. We formulate equations for calculating the effective radii of hydrometeors based on their characteristics, and we implement them in the WDM6 scheme to test the effect of this development on the simulation of radiative fluxes and precipitation for short-term weather forecasting.

\section{Method for Calculating Effective Radii of Hydrometeors}

The WDM6 scheme includes prognostic calculations of cloud droplets, rain, cloud ice, snow, and graupel by accounting for the aerosol effects on cloud properties and the precipitation processes, and it produces cloud condensation nuclei (CCN), cloud water, and rain drop number concentrations $[9,15]$. An ice process follows the WRF single-moment 6-class (WSM6) microphysics scheme [16] that the number concentration of ice particles is diagnosed with the mixing ratio of ice based on the equation derived from the ice's terminal velocity and mass-diameter relationship. A snow size distribution is assumed to be exponential with the intercept of snow $\left(n_{0 s}\right)$ as a function of temperature such that $n_{0 s}$ increases as the temperature decreases, and vice versa. The slope parameter for the size distribution of snow varies with the temperature and the mixing ratio of snow $[17,18]$.

Coupling the microphysics scheme to the RRTMG radiation scheme requires a calculation of hydrometeors' effective radii, which is performed using the equations below. The effective radius of cloud water $\left(R_{\text {effc }}\right)$ is calculated with the following equation:

$$
R_{\mathrm{effc}}=\frac{1}{2} \frac{\int_{-\infty}^{\infty} D_{c}^{3} n\left(D_{c}\right) d D_{c}}{\int_{-\infty}^{\infty} D_{c}^{2} n\left(D_{c}\right) d D_{c}}
$$

where $D_{c}$ and $n\left(D_{c}\right)$ are the radius and size distribution of the cloud droplet, respectively. The size distribution is a normalized form, and it can be expressed as

$$
n\left(D_{c}\right)=\frac{N_{c} \alpha_{c}}{\Gamma\left(\nu_{c}\right)} \lambda_{c}^{\alpha_{c} v_{c}} D_{c}^{\alpha_{c} \nu_{c}-1} \exp \left\{-\left(\lambda_{c} D_{c}\right)^{\alpha_{c}}\right\},
$$

where $N_{c}$ is the number concentration of cloud droplets and $\alpha_{c}$ and $\nu_{c}$ are dispersion parameters for the size distribution with values of $\alpha_{c}=3$ and $\nu_{c}=1 . \lambda_{c}$ is a slope parameter [9], and it is defined as follows:

$$
\lambda_{c}=\left[\frac{\pi}{6} \rho_{w} \frac{\Gamma\left(\nu_{c}+3 / \alpha_{c}\right)}{\Gamma\left(\nu_{c}\right)} \frac{N_{c}}{\rho_{a} Q_{c}}\right]^{1 / 3},
$$

where $\rho_{w}$ and $\rho_{a}$ are water and air density in $\mathrm{kg} \mathrm{m}^{-3}$, respectively. $Q_{c}$ is the mixing ratio of cloud water in $\mathrm{kg} \mathrm{kg}^{-1}$. By substituting (2) into (1), the effective radius of cloud water can be obtained as

$$
R_{\mathrm{effc}}=\left(2 \Gamma\left(\frac{3}{5}\right) \lambda_{c}\right)^{-1} .
$$

The number concentration $\left(N_{i}\right)$ and the maximum dimension of cloud ice $\left(D_{i, \mathrm{MAX}}\right)$ can be expressed as a function of the mass concentration of the cloud ice $\left(\rho Q_{i}\right)[19]$. The shape of the cloud ice is assumed to be a single bullet. Mitchell et al. [20] showed an equation for the effective radius of cloud ice as a function of the maximum dimension. That equation slightly changes with the shape of the cloud ice. The effective radius of the ice $\left(R_{\text {effi }}\right)$ applied in this study is

$$
R_{\text {effi }}=\frac{3}{4} 0.163 D_{i, \mathrm{MAX}} \text {. }
$$

For snow, several assumptions are applied to calculate the effective radius. (1) The shape of the snow is a hexagonal plate, (2) the ratio of the height to the diameter of the snow is 0.1 $(L / 2 a=0.1)$, and (3) the diameter of the hexagonal snow is the same as the mean-volume diameter of snow calculated in the single-moment scheme $\left(2 a=D_{s}\right)$. The size distribution of snow is assumed to be exponential with the slope parameter $\left(\lambda_{s}\right)$, which is given by

$$
\lambda_{s}=\left[\frac{\pi \rho_{s} n_{0 s}}{\rho Q_{s}}\right]^{1 / 4} .
$$

Here, $\rho_{s}$ is the density of the snow, and $Q_{s}$ is the mixing ratio of the snow. The intercept value of the snow size distribution depends on the temperature as shown in Hong and Lim [16]. The effective radius of snow is the ratio of the volume to the cross section. The equations for the geometric cross section $(A)$ and volume $(V)$ are shown in Liou et al. [21] as follows:

$$
\begin{aligned}
& A=\frac{3 a^{2}[\sqrt{3}+4(L / 2 a)]}{4}, \\
& V=3 \sqrt{3} a^{3} \frac{L}{2 a} .
\end{aligned}
$$




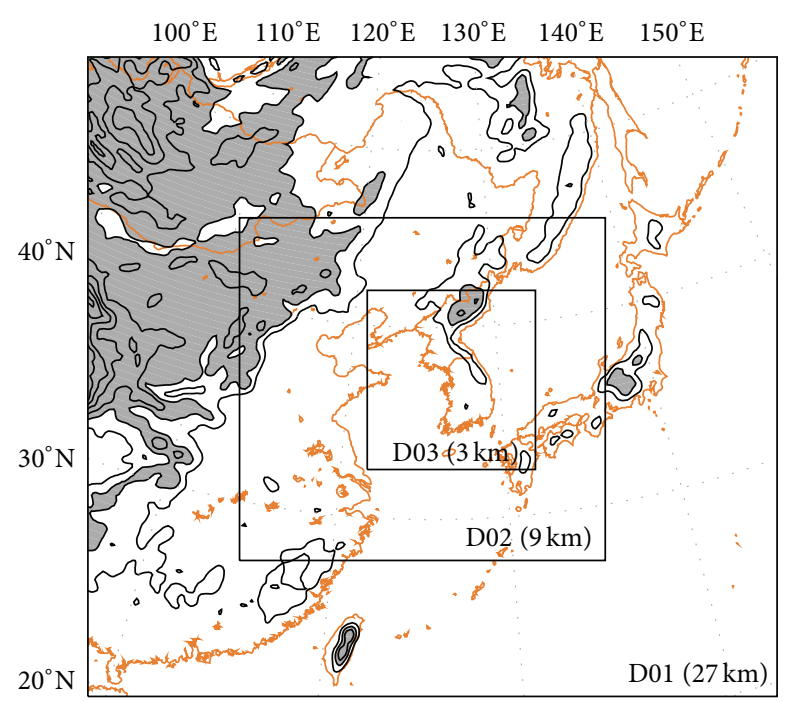

FIGURE 1: Model domain for $27 \mathrm{~km}$ resolution experiment (D01) with terrain heights contoured every $500 \mathrm{~m}$. Terrain heights greater than $1000 \mathrm{~m}$ are shaded. The inner boxes represent the domains for the $9 \mathrm{~km}$ (D02) and $3 \mathrm{~km}$ (D03) resolution experiments, respectively.

Applying the assumptions above to (7), we obtain the effective radius of snow $\left(R_{\text {effs }}\right)$ as follows:

$$
R_{\mathrm{effs}}=\frac{(L / 2 a)(9 \sqrt{3} / 4)}{(3 / 8)(\sqrt{3}+4 \times(L / 2 a))} \frac{1}{\lambda_{s}} \approx \frac{1}{2 \lambda_{s}} .
$$

The effective radius of cloud water for the single-moment scheme (WSM3, WSM5, and WSM6) uses a different equation from that for the double-moment scheme. The cloud size distribution is assumed to be the same as that of the rain, which is the exponential form. $N_{c}$ used in this study is $300 \mathrm{~cm}^{-3}$ [22]. The effective radius of cloud water for the single-moment scheme is obtained simply as $3 / 2 \lambda_{c}$. The effective radii of ice and snow for the single-moment scheme are the same as those for the WDM6 scheme.

\section{Numerical Experimental Setup}

A significant amount of rainfall was recorded over the midwestern region of the Korean Peninsula from 26 to 28 July 2011 with a local maximum of approximately $587.5 \mathrm{~mm}$. Most rainfall occurred during the 24-hour period from 1200 UTC 26 July to 1200 UTC 27 July, with a local maximum of about $449.5 \mathrm{~mm} \mathrm{day}^{-1}$ [23]. At 1200 UTC 26 July 2011, typical synoptic scale features for a heavy rainfall development were observed. Low-level jets between the western Pacific subtropical high and the low-pressure system over central China brought warm and moist air from the Yellow Sea to the Korean Peninsula. The low-level jet with moist, warm air and a low-pressure trough in north China with dry and cold air rapidly developed a heavy rain cloud in the middle region of the Korean Peninsula $[23,24]$. A more detailed synoptic overview of this heavy rainfall event was described in Jang and Hong [24].

The model used in this study is the Advanced Research WRF (ARW) version 3.6 [25] released in April 2014, which is constructed based on a fully compressible and nonhydrostatic dynamic core. The model uses a terrain-following hydrostatic pressure coordinate, and horizontal resolutions of the models are 27,9 , and $3 \mathrm{~km}$ for one-way nesting. The $3 \mathrm{~km}$ model covers the Korean Peninsula (Domain 3, $355 \times 352$ ) which is surrounded by the $9 \mathrm{~km}$ grid model (Domain 2, $259 \times$ 223). Domain 2 is nested inside the $27 \mathrm{~km}$ grid model in turn (Domain 1, $178 \times 150$ ) (Figure 1). The number of vertical layers is 51 from the surface to $50 \mathrm{hPa}$. The simulation period is from 1200 UTC 25 July to 1200 UTC 27 July 2011. Initial and boundary conditions are from the NCEP Final (FNL) operational global analysis data on $1.0^{\circ} \times 1.0^{\circ}$ resolutions, and the boundary conditions are forced every $6 \mathrm{~h}$.

Along with the WDM6 and RRTMG schemes for the microphysics and radiation simulations, the physical options used in this study are the Kain-Fritsch [26] deep cumulus parameterization scheme, the Global/Regional Integrated Modeling system (GRIMs) shallow convection scheme [27], the Noah land surface model $[28,29]$, and the Yonsei University Planetary Boundary Layer (PBL) with nonlocal turbulent mixing [30]. No cumulus parameterization is used for the $3 \mathrm{~km}$ grid model.

Two simulations for a heavy rainfall case are carried out including control and sensitivity simulations. The first is conducted with the original WRF model and the latter is conducted with the model using the coupled WDM6RRTMG. We focus our analysis on the results of these two simulations for Domain 3. All the values below are averaged values for 1200 UTC 26 July to 1200 UTC 27 July 2011.

\section{Results}

We first analyze simulated cloud optical depths, which are important for affecting the radiative fluxes and depend on the liquid/ice water path and the effective radii of the hydrometeors. To examine the sensitivity of the simulated results to the effective radius of hydrometeors, we analyze 


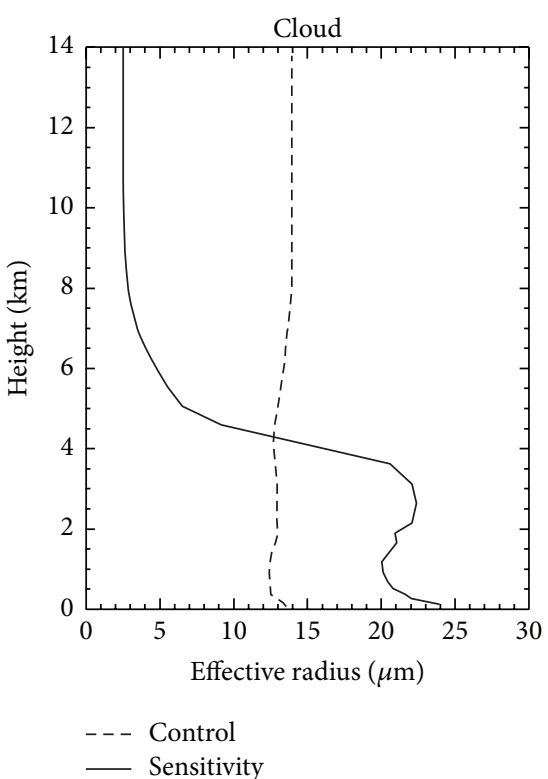

(a)

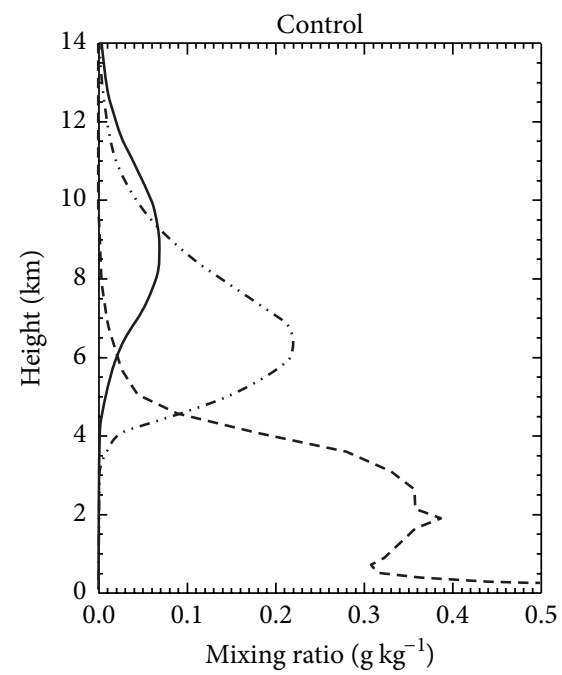

(d)

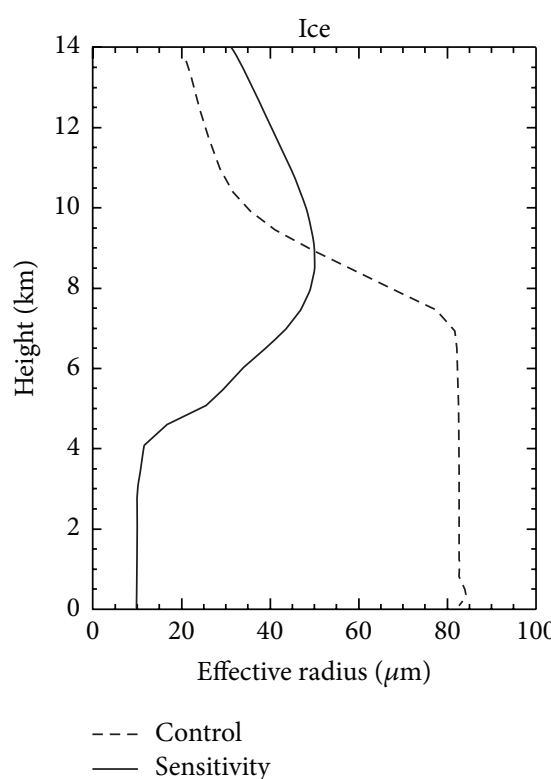

(b)

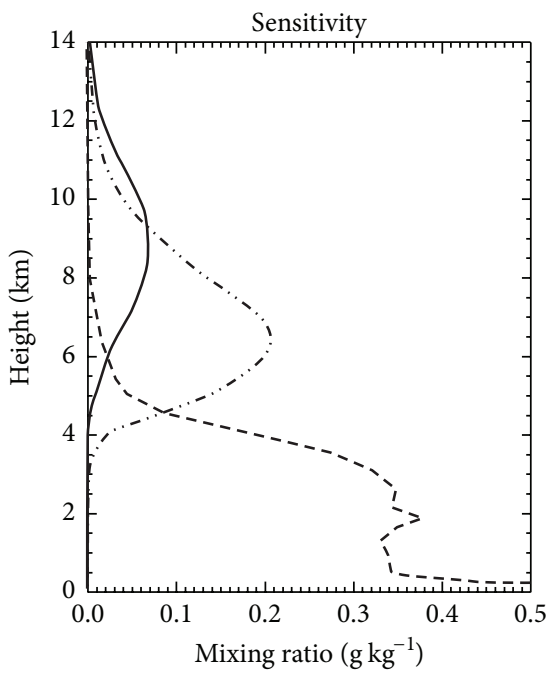

(e)

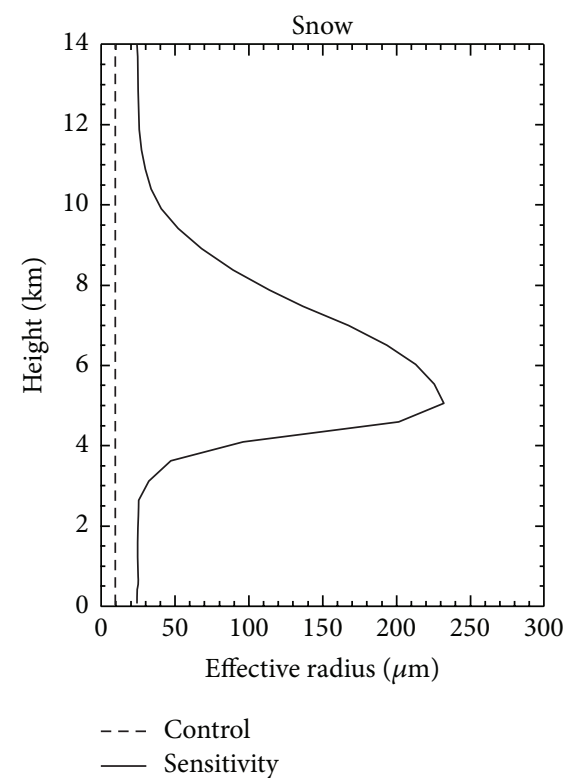

(c)

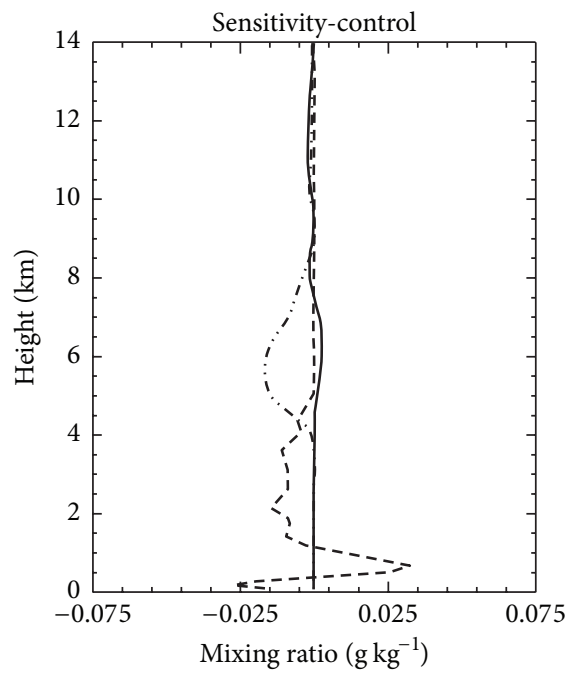

(f)

FIGURE 2: (a, b, c) Vertical distribution of effective radii of cloud water (a), cloud ice (b), and snow (c) for control (dashed line) and sensitivity (solid line). (d, e, f) Hydrometeors for control (d) and sensitivity (e), and differences between two experiments (f). $Q_{c}$ is the mixing ratio of cloud water, $Q_{i}$ is that of cloud ice, and $Q_{s}$ is that of snow. These values are averaged from 1200 UTC 26 July to 1200 UTC 27 July 2011 over the cloudy area $\left(Q_{c}+Q_{i}+Q_{s}>0.001 \mathrm{~g} \mathrm{~kg}^{-1}\right)$.

(1) the differences in the effective radii and mixing ratios of hydrometeors, (2) resulting shortwave fluxes reaching the ground (solar insolation, SWDOWN) and outgoing longwave fluxes at top of the atmosphere (OLR), and (3) differences in the 24-hour accumulated precipitation fields between the control and sensitivity simulations.

Figure 2 shows the vertical distribution of the mean effective radii of cloud, ice, and snow from both the control and sensitivity simulations. Values are averaged over the cloudy area for a 1-day integration time period. The cloudy area is defined as model grid boxes where the sum of the mixing ratios of cloud water $\left(Q_{c}\right)$, cloud ice $\left(Q_{i}\right)$, and snow $\left(Q_{s}\right)$ is higher than $0.001 \mathrm{~g} \mathrm{~kg}^{-1}$, and it is also shown in
Figure 2. The mean effective radii of cloud water from the control experiment do not vary much with altitude, whereas the sensitivity simulation shows considerable variation of simulated effective radii $(5-25 \mu \mathrm{m})$. For example, the radius of about $20 \mu \mathrm{m}$ is shown below $2 \mathrm{~km}$ due to the high mixing ratio of cloud water (Figure 2). The simulated values are generally large at low altitudes $(<4 \mathrm{~km})$ and are decreased significantly above $6 \mathrm{~km}$ mainly because no cloud droplets are present. The vertical change of the effective radii from the sensitivity simulation is more consistent with the observations measured by aircraft and satellites [31].

On the other hand, the cloud ice's effective radii in the sensitivity simulation are more consistent with the vertical 

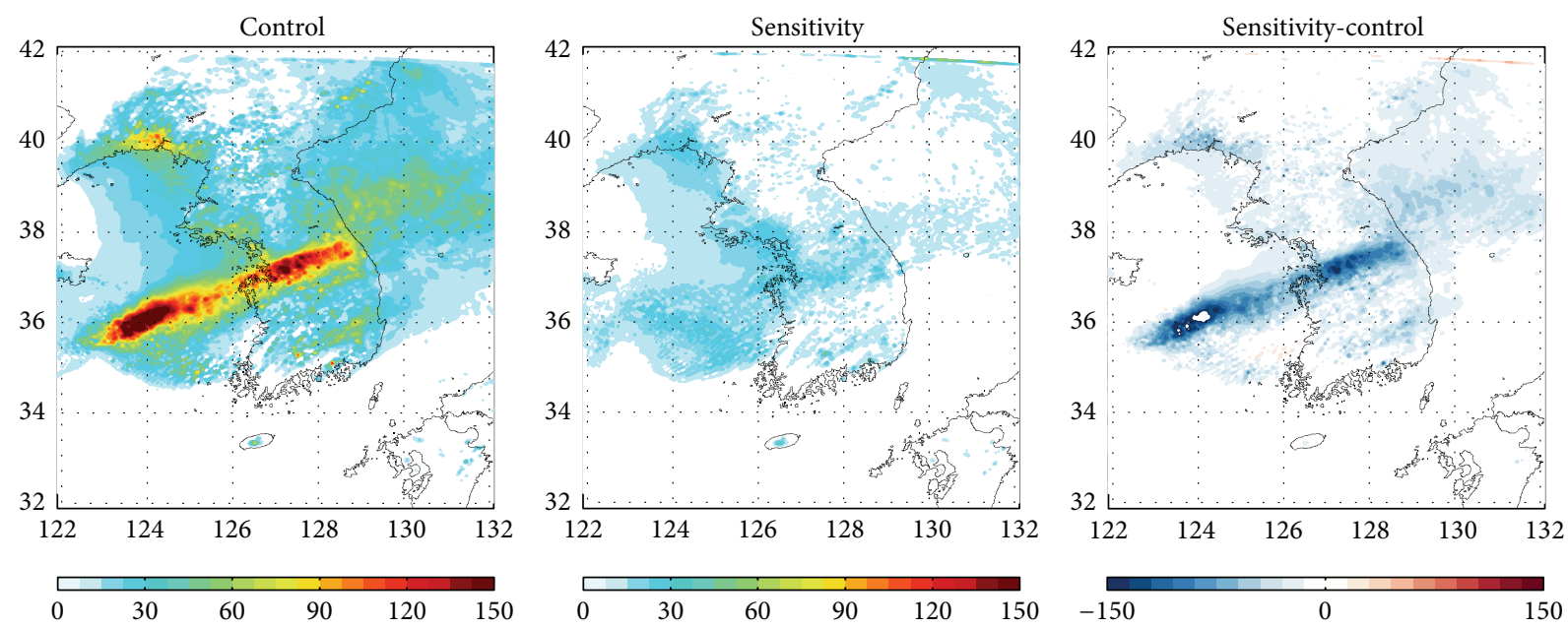

(a)
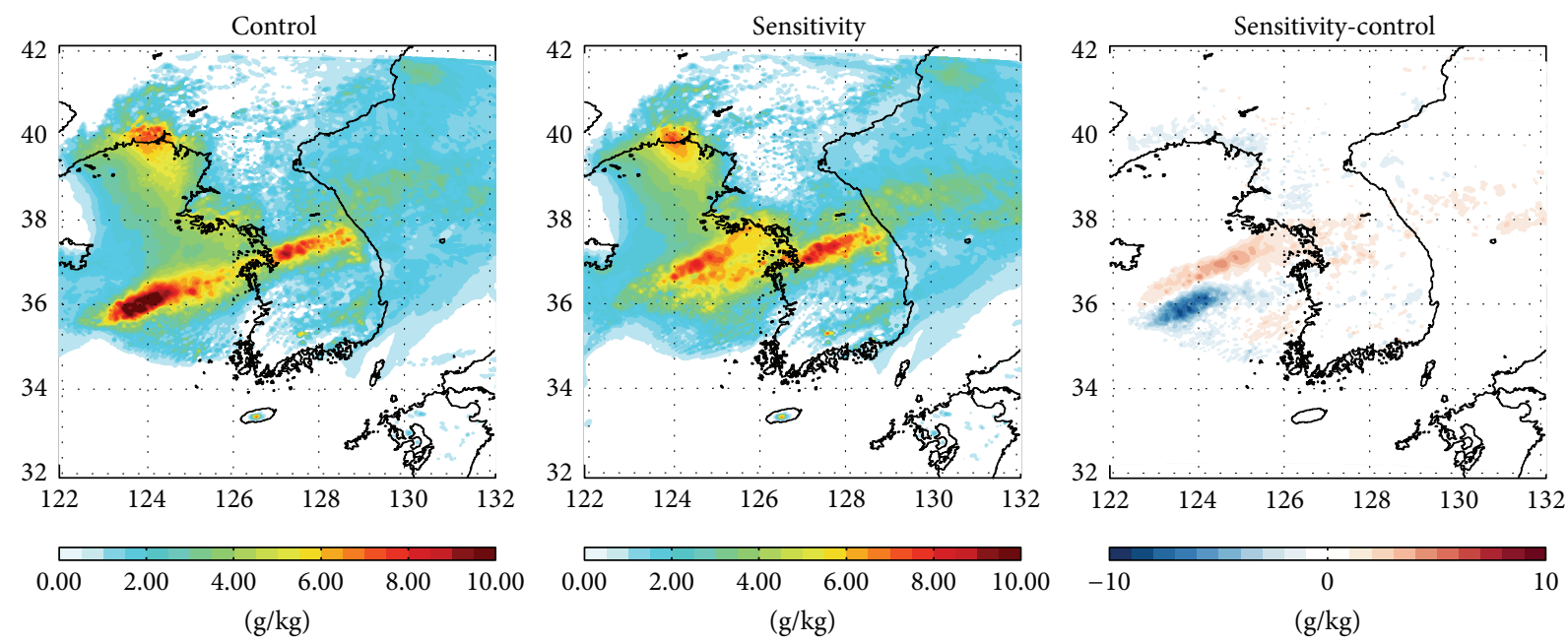

(b)

FiguRE 3: Cloud optical depth for 3.84-12.195 $\mu \mathrm{m}$ wavelength of shortwave (a) and total mixing ratio of $Q_{c}$, $Q_{i}$, and $Q_{s}$ (b) vertically added below $14 \mathrm{~km}$ height for control and sensitivity simulations.

distribution of its mixing ratio, which increases at $4-8 \mathrm{~km}$ and decreases above $8 \mathrm{~km}$. The control run, however, shows an opposite vertical distribution of the effective radii with the height owing to a decrease in air temperature. The effective radius of cloud ice in the sensitivity experiment does not sharply decrease, unlike the mixing ratio of cloud ice above $8 \mathrm{~km}$. This is why WDM6 calculates the number concentrations of cloud ice as a function of $Q_{i}$ [19]. McFarquhar and Heymsfield [32] showed the aircraft-observed effective radius, which varies in the range of $30-60 \mu \mathrm{m}$ for ice crystals. We find that the vertical distribution of the effective radius is consistent with that of the ice water content with altitudes.

As discussed above, the effective radius of snow in the control experiment is fixed with the value of $10 \mu \mathrm{m}$. However, we find a dramatic change of snow size in the sensitivity simulation such that it peaks around $5 \mathrm{~km}$, where the highest snow mixing ratio occurs. The snow's effective radius in the sensitivity simulation is always larger than that in the control simulation.
Figure 3 shows resulting cloud optical depths and total mixing ratio $\left(Q_{c}+Q_{i}+Q_{s}\right)$ vertically integrated below $14 \mathrm{~km}$ from the two simulations. First, we find that the simulated cloud optical depths show a significant change between the two models. The sensitivity simulation shows much reduced cloud optical depths relative to the control model caused by changes in the water content and effective radii of hydrometeors. The effective radii of the hydrometeors from the sensitivity model are closer to the observed values than those of the control simulation. In Figure 2, the ice and snow exist mainly between 6 and $12 \mathrm{~km}$ for both simulations. The mixing ratio of these hydrometeors in the sensitivity experiment is slightly decreased compared to the control experiment at $5-10 \mathrm{~km}$. The effective radii of cloud ice and snow in the sensitivity simulation are larger than those in the control at these heights, and the cloud optical depth is a function of water path $/ R_{\text {eff }}$. RRTMG computes the optical depth of cloud water, ice droplets, and snow in the same way. Therefore, we can expect that the cloud optical depth in the 

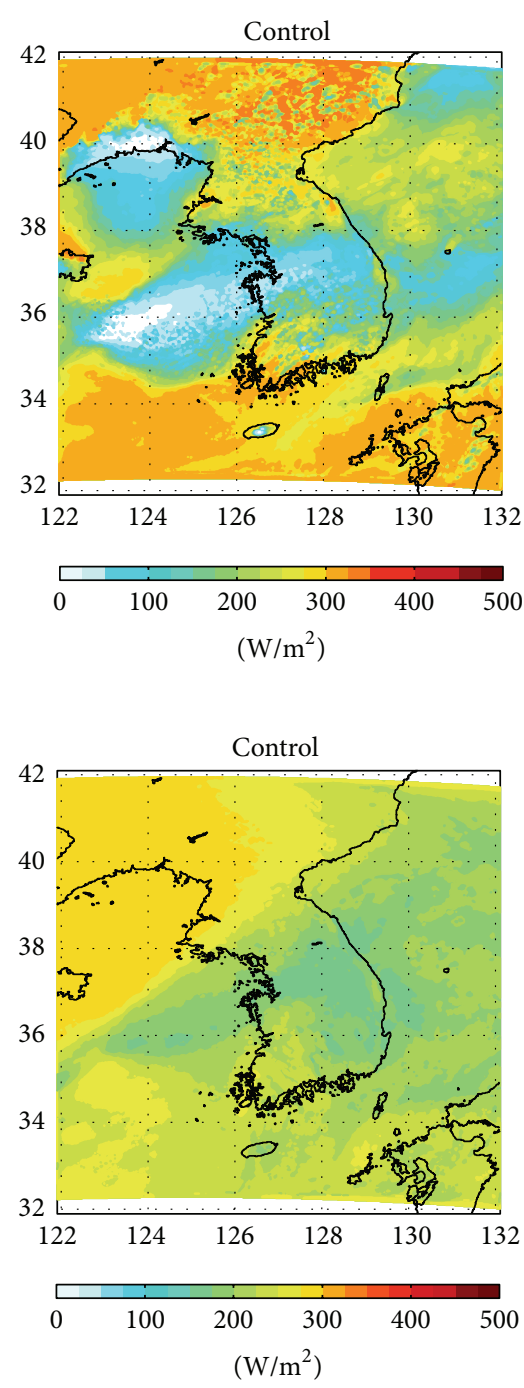

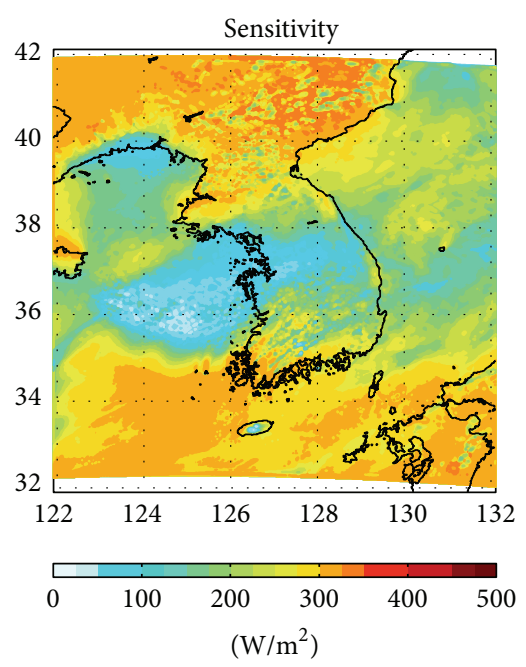

(a)

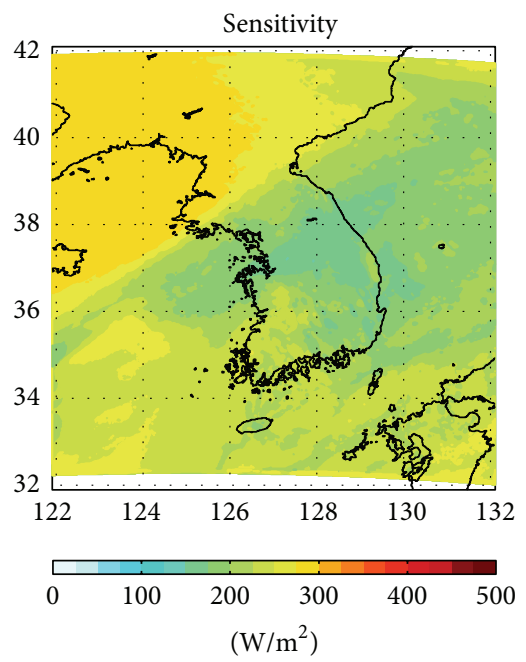

(b)
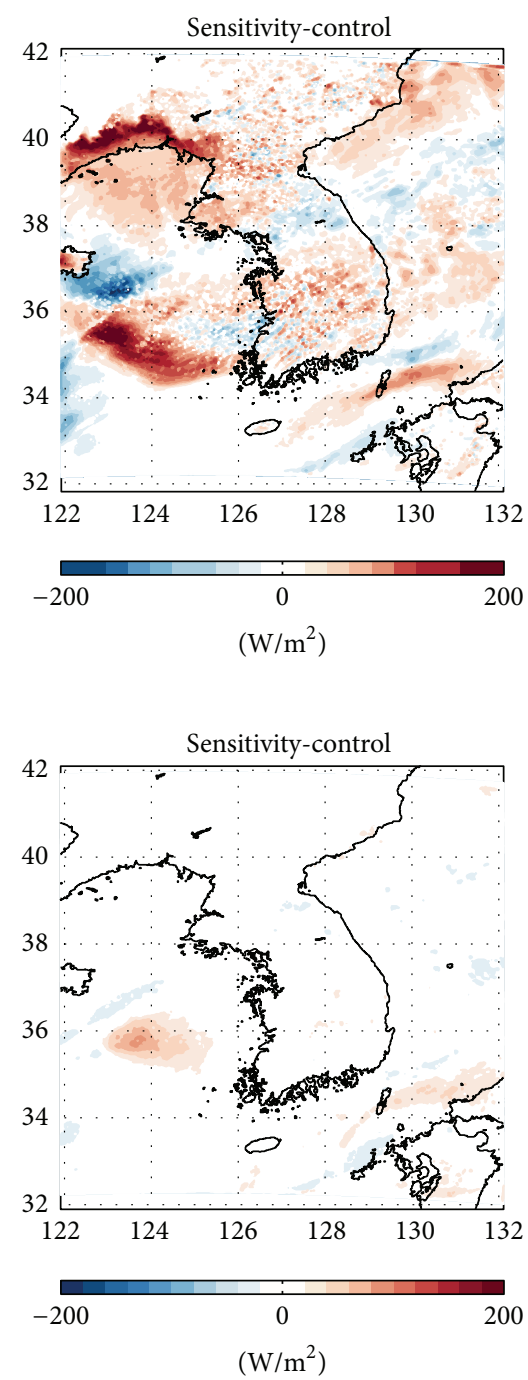

$\left(\mathrm{W} / \mathrm{m}^{2}\right)$

FIGURE 4: Comparison of shortwave fluxes reaching ground (SWDOWN) (a) and outgoing longwave fluxes at top of atmosphere (OLR) (b) for control and sensitivity simulations.

sensitivity simulation will be mostly decreased compared to that of the control simulation.

To examine the effect of the effective radii changes on radiative fluxes, we compare the SWDOWN and OLR (Figure 4). SWDOWN and OLR in the sensitivity simulation generally increase to those in the control, because the cloud optical depth decreases, as mentioned earlier. The increase of SWDOWN in the sensitivity simulation is also shown in Figure 5. The overall distribution from the two simulations is not affected but the frequency of SWDOWN smaller than $100 \mathrm{~W} \mathrm{~m}^{-2}$ in the sensitivity simulation decreases by about $1-3 \%$, while the frequency of SWDOWN larger than $300 \mathrm{~W} \mathrm{~m}^{-2}$ increases as compared to the values from the control. It is noted that the increase of OLR is distinct over the Yellow Sea around $36^{\circ} \mathrm{N}$ where differences in microphysics are pronounced (see Figure 3). As seen later, this is where precipitation is reduced in the sensitivity experiment. We guess that relative heating due to enhanced SWDOWN plays a role in the increased evaporation of falling hydrometeors. The difference in SWDOWN between the sensitivity and control simulations is larger than that in OLR, indicating that SWDOWN is more affected by the effective radii changes of hydrometeors than OLR. Therefore, we analyze the effect of the effective radius on the radiative flux, focusing on SWDOWN. Simulated and observed SWDOWN fluxes are compared to evaluate the model. The observed SWDOWN is from the Communication, Ocean, and Meteorological Satellite (COMS) provided by the National Meteorological Satellite Center at 0000 UTC 27 July 2011 (0900 LST 27 July 2011) of the target time (second simulation day); it is selected to show the effect of WDM6-RRTMG coupling on shortwave fluxes. COMS is Korea's first geostationary multipurpose satellite, and it was launched in June 2010. It is stationed at an altitude of $36,000 \mathrm{~km}$ above the Earth's equator and at a longitude of $128.2^{\circ} \mathrm{E}$, and it performs duties such as meteorological and ocean observations and communications services. It has five 


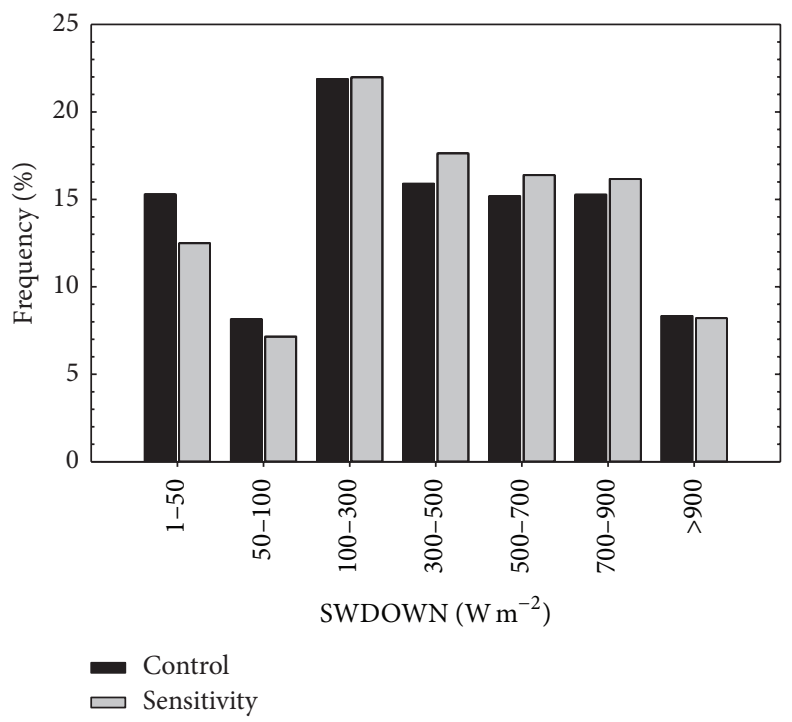

FIGURE 5: Probability density functions (PDFs) of SWDOWN for second simulation day.

channels (one visible and four infrared (IR)), and it performs observations at intervals of less than 27 minutes [33].

Figure 6 shows a COMS IR image for 0000 UTC 27 July 2011. The brighter color indicates high clouds with low cloud top temperature. For example, at middle latitudes, low cloud is shown as dark gray, middle cloud as light gray, and high cloud as white. As shown in Figure 5, middle and high clouds cover most parts of the Korean Peninsula and its surroundings. However, cloud is rarely found over the Bohai Sea and the western sea of the Korean Peninsula, which is consistent with the high SWDOWN fluxes from the sensitivity simulation. In order to further validate the simulated SWDOWN fluxes, we use the solar insolation of COMS retrieved using the Kawamura Model [34] optimized for the East Asia region [35]. Baek et al. [36] previously showed that correlations between COMS and ground-based observation were high in both 30-minute interval data and daily average data. They identified that COMS can provide a reasonable estimation of solar insolation over the Korean Peninsula. The observed SWDOWN in these areas has a typical range of 150$450 \mathrm{~W} \mathrm{~m}^{-2}$. The simulated SWDOWN in the control experiment shows a significant disparity from the observations. In particular, SWDOWN over the Yellow Sea is too low, but that in the East Sea is higher than the observation. We find that SWDOWN in the sensitivity experiment is higher (by up to $500 \mathrm{~W} \mathrm{~m}^{-2}$ ) over the Yellow Sea and lower in the East Sea, which is more consistent with the observations.

Figure 7 shows a comparison between the observed and simulated 24-hour accumulated precipitation. The observation is from the Tropical Rainfall Measuring Mission (TRMM) Multisatellite Precipitation Analysis (TMPA). The overall distribution of the 24-hour accumulated rainfall is not affected but its amount is changed. Total precipitation over whole domain is $332.8 \mathrm{~cm}$ and $340.4 \mathrm{~cm}$ for the control and sensitivity simulations, respectively. A spurious rainfall peak over the Yellow Sea is alleviated, whereas the local maximum in the central part of the Korean Peninsula is increased in the sensitivity simulation as compared to the control. It shows better agreement with the observation (Figure 7). In the control simulation, the precipitation over the Yellow Sea and the central region of the Korean Peninsula is more widely distributed southwest. Regions with increases of precipitation correspond to areas with decreases of SWDOWN, and vice versa (Figures 3 and 4). For example, a heavy rainfall band becomes stronger in the north of the Korean Peninsula and the East Sea around $38^{\circ} \mathrm{N}$, where significant SWDOWN decreases occur. In the Yellow Sea below $36^{\circ} \mathrm{N}$ where SWDOWN is high, precipitation is low because the increasing temperature (heating rate by microphysics process (Figure 8)) associated with SWDOWN flux changes leads to increase in evaporation and subsequent condensation processes in the Yellow Sea below $36^{\circ} \mathrm{N}$. As a result, the precipitation in the sensitivity simulation over these areas decreases and is more organized than in the control simulation. We also conducted 31 simulations for the verification of short-range precipitation forecasting during July 2011 for Domain 1 (27 km resolution); each simulation period is $48 \mathrm{~h}$. The Equitable Threat Score (ETS) and Bias Score (BIAS) are calculated with the 12-hour accumulated precipitation at 24 forecasting hours of each simulation against the Automated Surface Observing System (ASOS) measured in the Korea Meteorological Administration. However, the ETS and BIAS between the control and sensitivity simulations are not affected by the changes in effective radii based on hydrometeors' characteristics.

\section{Summary and Conclusion}

The physics consistency between the WDM6 microphysics scheme and the RRTMG radiation scheme is ensured by adding the computation subroutine for the effective radii and linking the WDM6 and RRTMG schemes in the WRF model. 


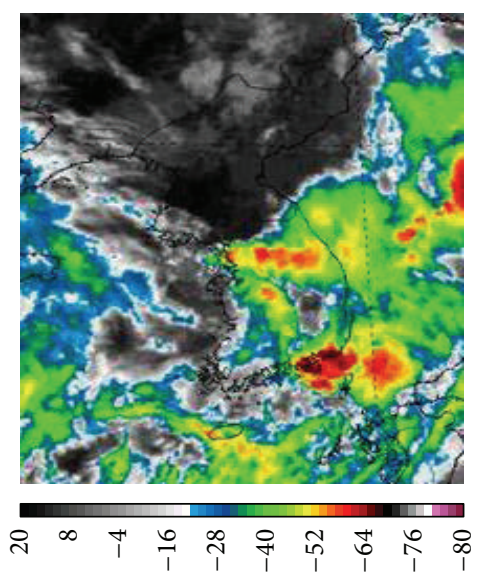

$\left({ }^{\circ} \mathrm{C}\right)$

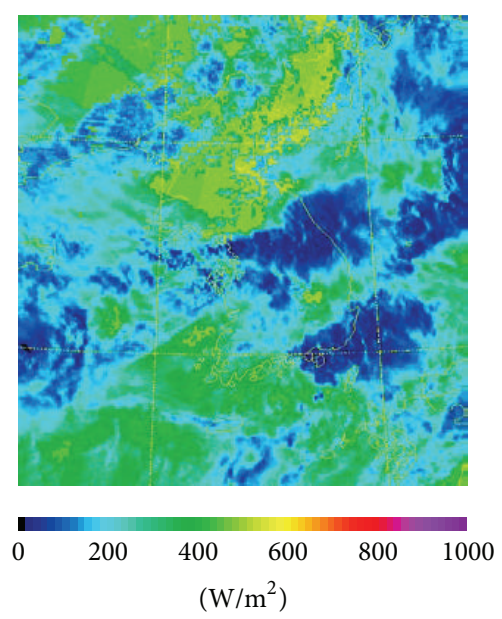

(b)

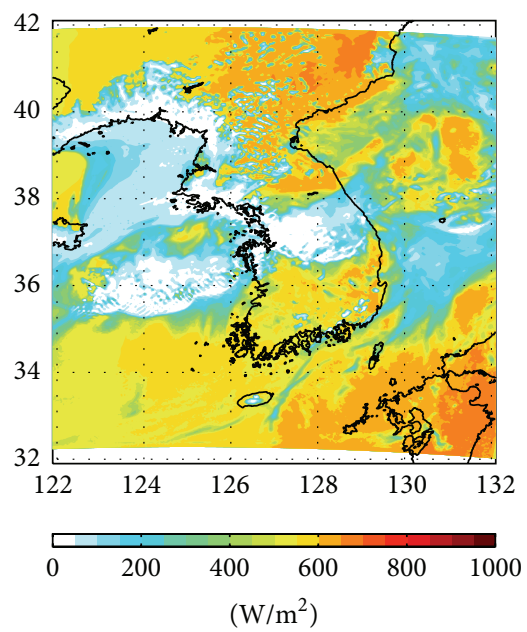

(c)

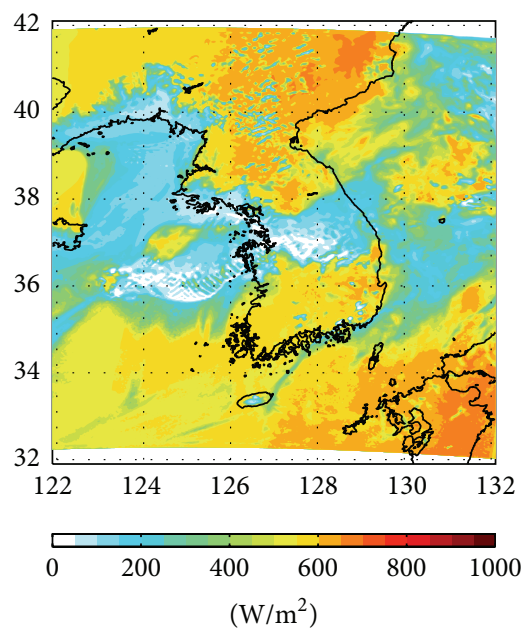

(d)

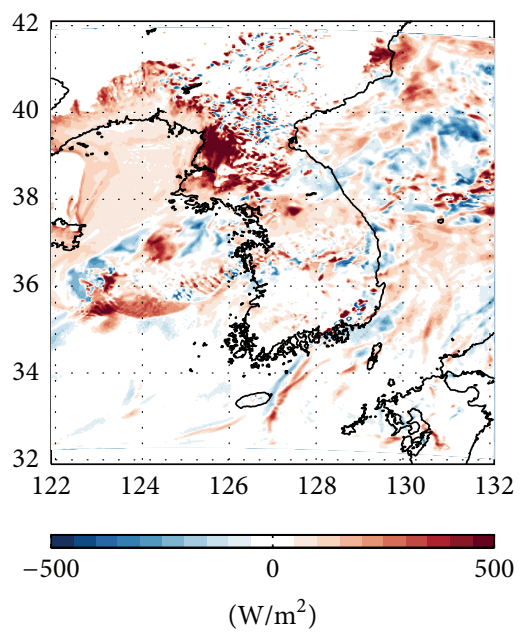

(e)

Figure 6: (a, b) Infrared image (a) and SWDOWN (b) retrieved from Communication, Ocean, and Meteorological Satellite (COMS) at 0000 UTC 27 July 2011 (National Meteorological Satellite Center in Korea and Meteorological Information Portal Service System of KMA). (c, d, e) SW fluxes reaching surface (SWDOWN) for control (c) and sensitivity (d) experiments and difference in SWDOWN between sensitivity and control (e) at the same time.

The WDM6 is the double-moment treatment for warm rain processes, and it includes the prognostics number and mass concentration of cloud droplets and rainwater. Ice processes predict the mass mixing ratio but the number concentration of ice is diagnosed with the mass-diameter relationship and the fall velocity. The effective radius is calculated based on the hydrometeors' characteristics.

The sensitivity simulations are performed for heavy rainfall events that occurred on 25-27 July 2011 to determine the effect of the modified effective radius on radiation and precipitation. The effective radii of cloud, ice, and snow simulated with modified code increased to reflect the hydrometeors' characteristics. The changed effective radius according to hydrometeors affects the radiative fluxes, especially the shortwave flux. The fluxes reaching the ground are improved by applying explicit radii variables in the RRTMG interface code, especially in areas that either are cloudless or have only a little cloud, such as the Bohai Sea and the Yellow Sea. The changed radiative fluxes affect air temperature, which lead to increase of precipitation.

The overall distribution of the 24-hour accumulated rainfall is not affected but its amount is changed. Total precipitation over the whole domain in the sensitivity simulation is larger than that in the control simulation. A spurious rainfall peak over the Yellow Sea is alleviated, whereas the local maximum in the central part of the Korean Peninsula is increased in the sensitivity simulation as compared to the control. Although the difference of precipitation between the sensitivity and control is not large, the results show that the precipitation in the sensitivity simulation is in better agreement with observations. The WSM/WDM schemes including the effective radii's subroutine were 


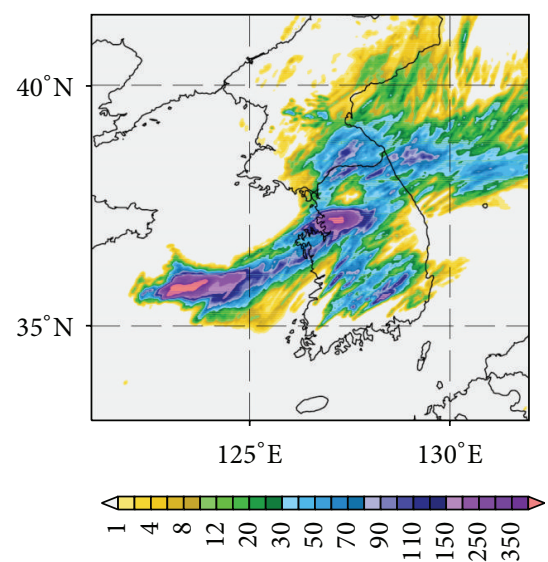

(a)

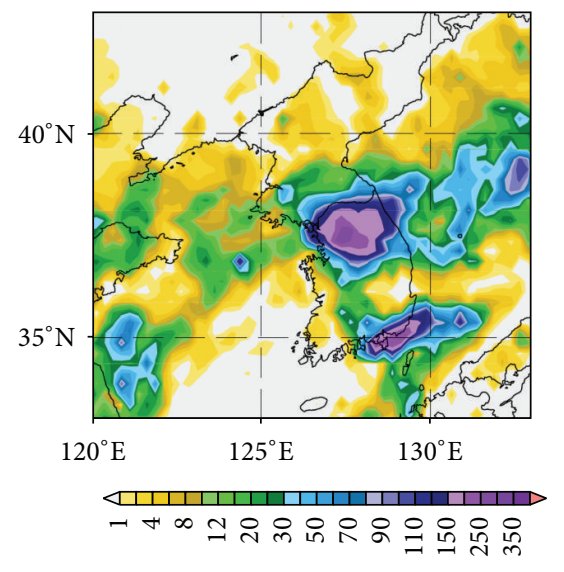

(c)

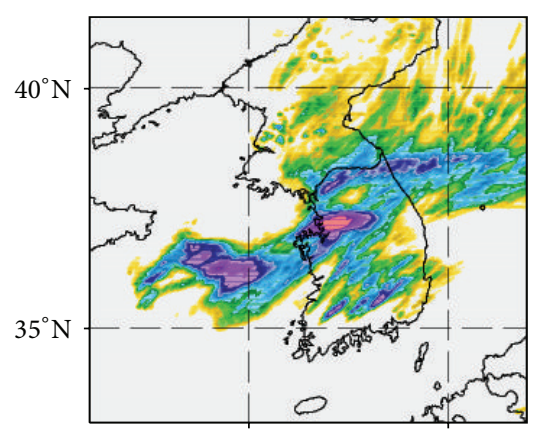

$130^{\circ} \mathrm{E}$

(b)

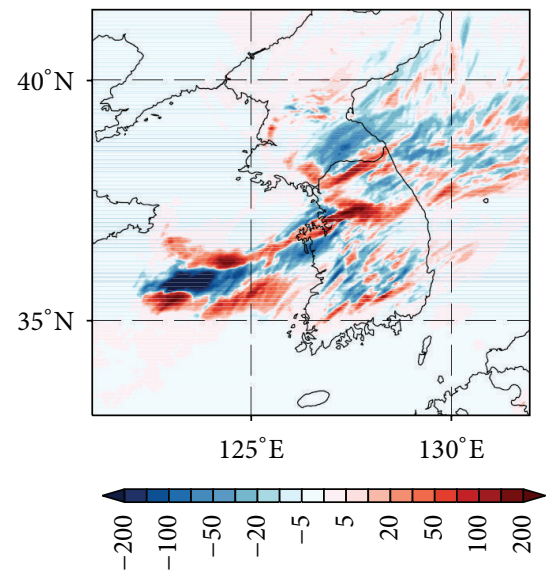

(d)

FIGURE 7: 24-hour accumulated precipitation of observations (c) and simulations ((a) and (b)). (a) is the simulated precipitation for the control, (b) is that for the sensitivity, and (d) is the difference between the sensitivity and control simulations. The observation is TMPA.
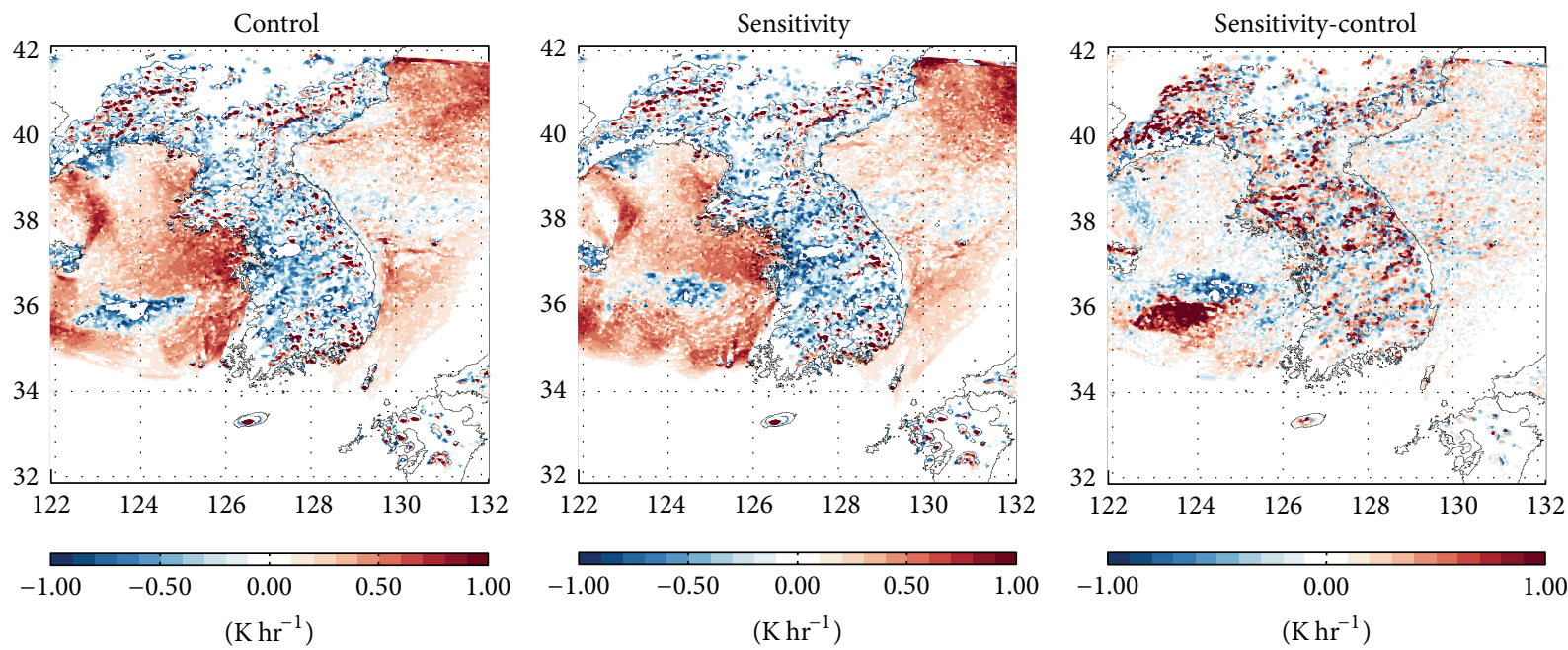

FIGURE 8: Heating rate by microphysics processes for control and sensitivity simulations at bottom layer averaged for second simulation period. 
implemented in WRF version 3.7, which was released in April 2015.

\section{Competing Interests}

The authors declare that they have no competing interests.

\section{Acknowledgments}

This work has been carried out through the R\&D project on the development of global numerical weather prediction systems of the Korea Institute of Atmospheric Prediction Systems (KIAPS) funded by the Korea Meteorological Administration (KMA). Pacific Northwest National Laboratory is operated for DOE by Battelle Memorial Institute under Contract DE-AC05-76RLO 1830.

\section{References}

[1] R. D. Cess, "Climate change: an appraisal of atmospheric feedback mechanisms employing zonal climatology," Journal of the Atmospheric Sciences, vol. 35, pp. 1765-1768, 1976.

[2] K. N. Liou, An Introduction to Atmospheric Radiation, Academic Press, 2nd edition, 2002.

[3] G. Thompson, M. Tewari, K. Ikeda et al., "Explicitly-coupled cloud physics and radiation parameterizations and subsequent evaluation in WRF high-resolution convective forecasts," Atmospheric Research, vol. 168, pp. 92-104, 2016.

[4] M. J. Iacono, J. S. Delamere, E. J. Mlawer, M. W. Shephard, S. A. Clough, and W. D. Collins, "Radiative forcing by long-lived greenhouse gases: calculations with the AER radiative transfer models," Journal of Geophysical Research Atmospheres, vol. 113, no. 13, Article ID D13103, 2008.

[5] Atmospheric and Environmental Research, Final Technical Report for Application of Improved Radiation Modeling to General Circulation Models, Atmospheric and Environmental Research, Lexington, Mass, USA, 2011.

[6] H. Barker, J. N. S. Cole, J.-J. Morcrette, R. Pincus, and P. Raisanen, "Monte Carlo Independent Column Approximation (McICA): up and running in North America and Europe," in Proceedings of the 17th Atmospheric Radiation Measurement (ARM) Science Team Meeting, Monterey, Calif, USA, March 2007.

[7] R. Pincus, H. W. Barker, and J.-J. Morcrette, "A fast, flexible, approximate technique for computing radiative transfer in inhomogeneous cloud fields," Journal of Geophysical Research, vol. 108, no. 13, 2003.

[8] G. Thompson, P. R. Field, R. M. Rasmussen, and W. D. Hall, "Explicit forecasts of winter precipitation using an improved bulk microphysics scheme. Part II: implementation of a new snow parameterization," Monthly Weather Review, vol. 136, no. 12, pp. 5095-5115, 2008.

[9] K.-S. S. Lim and S.-Y. Hong, "Development of an effective double-moment cloud microphysics scheme with prognostic cloud condensation nuclei (CCN) for weather and climate models," Monthly Weather Review, vol. 138, no. 5, pp. 1587-1612, 2010.

[10] H. Morrison, G. Thompson, and V. Tatarskii, "Impact of cloud microphysics on the development of trailing stratiform precipitation in a simulated squall line: comparison of one- and twomoment schemes," Monthly Weather Review, vol. 137, no. 3, pp. 991-1007, 2009.
[11] H. Morrison and J. A. Milbrandt, "Comparison of two-moment bulk microphysics schemes in idealized supercell thunderstorm simulations," Monthly Weather Review, vol. 139, no. 4, pp. 11031130, 2011.

[12] J.-H. Kim, D.-B. Shin, and C. Kummerow, "Impacts of a priori databases using six WRF microphysics schemes on passive microwave rainfall retrievals," Journal of Atmospheric and Oceanic Technology, vol. 30, no. 10, pp. 2367-2381, 2013.

[13] C. Lin, Evaluation of double-moment representation of warmrain and ice hydrometeors in bulk microphysical parameterization [M.S. thesis], The University of Utah, Salt Lake City, Utah, USA, 2014.

[14] H. Morrison, J. A. Milbrandt, G. H. Bryan, K. Ikeda, S. A. Tessendorf, and G. Thompson, "Parameterization of cloud microphysics based on the prediction of bulk ice particle properties. Part II: case study comparisons with observations and other schemes," Journal of the Atmospheric Sciences, vol. 72, no. 1, pp. 312-339, 2015.

[15] S.-Y. Hong, K.-.S. S. Lim, Y.-H. Lee et al., "Evaluation of the WRF double-moment 6-class microphysics scheme for precipitating convection," Advances in Meteorology, vol. 2010, Article ID 707253, 10 pages, 2010.

[16] S.-Y. Hong and J.-O. J. Lim, "The WRF single-moment 6class microphysics scheme (WSM6)," Journal of the Korean Meteorological Society, vol. 42, pp. 129-151, 2006.

[17] R. A. Houze Jr., P. V. Hobbs, P. H. Herzegh, and D. B. Parsons, "Size distributions of precipitation particles in frontal clouds," Journal of the Atmospheric Sciences, vol. 36, no. 1, pp. 156-162, 1979.

[18] B. F. Ryan, "On the global variation of precipitating layer clouds," Bulletin of the American Meteorological Society, vol. 77, no. 1, pp. 53-70, 1996.

[19] S.-Y. Hong, J. Dudhia, and S.-H. Chen, "A revised approach to ice microphysical processes for the bulk parameterization of clouds and precipitation," Monthly Weather Review, vol. 132, no. 1, pp. 103-120, 2004.

[20] D. L. Mitchell, A. Macke, and Y. Liu, "Modeling cirrus clouds. Part II: treatment of radiative properties," Journal of the Atmospheric Sciences, vol. 53, no. 20, pp. 2967-2988, 1996.

[21] K. N. Liou, Y. Takano, C. He et al., "Stochastic parameterization for light absorption by internally mixed $\mathrm{BC} /$ dust in snow grains for application to climate models," Journal of Geophysical Research: Atmospheres, vol. 119, no. 12, pp. 7616-7632, 2014.

[22] J. G. Hudson and S. Noble, "CCN and cloud droplet concentrations at a remote ocean site," Geophysical Research Letters, vol. 36, no. 13, Article ID L13812, 2009.

[23] Korea Meteorological Administration, 2011: Heavy rainfall events top 10, KMA registered Pub., No. 11-136000-000833-01, Seoul (in Korean).

[24] J. Jang and S.-Y. Hong, "Quantitative forecast experiment of a heavy rainfall event over Korea in a global model: horizontal resolution versus lead time issues," Meteorology and Atmospheric Physics, vol. 124, no. 3-4, pp. 113-127, 2014.

[25] W. C. Skamarock, J. B. Klemp, J. Dudhia et al., "A description of the advanced research WRF version 3," NCAR Technical Note NCAR/TN-475+STR, UCAR Staff Directory, New York, NY, USA, 2008.

[26] J. S. Kain and J. Kain, "The Kain-Fritsch convective> parameterization: An update," Journal of Applied Meteorology, vol. 43, no. 1, pp. 170-181, 2004. 
[27] S.-Y. Hong, H. Park, H.-B. Cheong et al., "The global/regional integrated model system (GRIMs)," Asia-Pacific Journal of Atmospheric Sciences, vol. 49, no. 2, pp. 219-243, 2013.

[28] F. Chen and J. Dudhia, "Coupling an advanced land surfacehydrology model with the Penn State-NCAR MM5 modeling system. Part I: model implementation and sensitivity," Monthly Weather Review, vol. 129, no. 4, pp. 569-585, 2001.

[29] M. B. Ek, K. E. Mitchell, Y. Lin et al., "Implementation of Noah land surface model advances in the National Centers for Environmental Prediction operational mesoscale Eta model," Journal of Geophysical Research D: Atmospheres, vol. 108, no. 22, pp. 1-16, 2003.

[30] S.-Y. Hong, Y. Noh, and J. Dudhia, "A new vertical diffusion package with an explicit treatment of entrainment processes," Monthly Weather Review, vol. 134, no. 9, pp. 2318-2341, 2006.

[31] D. Painemal and P. Zuidema, "Assessment of MODIS cloud effective radius and optical thickness retrievals over the Southeast Pacific with VOCALS-REx in situ measurements," Journal of Geophysical Research Atmospheres, vol. 116, no. 24, Article ID D24206, 2011.

[32] G. M. McFarquhar and A. J. Heymsfield, "The definition and significance of an effective radius for ice clouds," Journal of the Atmospheric Sciences, vol. 55, no. 11, pp. 2039-2052, 1998.

[33] National Meteorological Satellite Center, http://nmsc.kma.go .kr.

[34] H. Kawamura, S. Tanahashi, and T. Takahashi, "Estimation of insolation over the Pacific Ocean off the Sanriku Coast," Journal of Oceanography, vol. 54, no. 5, pp. 457-464, 1998.

[35] National Institute of Meteorological Research, Development of Meteorological Data Processing System of Communication, Ocean and Meteorological Satellite, Korea Meteorological Administration, 2007.

[36] J. Baek, K. Byun, D. Kim, and M. Choi, "Assessment of solar insolation from COMS: sulma and Chengmi watersheds," Korean Journal of Remote Sensing, vol. 29, pp. 137-150, 2013 (Korean with English abstract). 

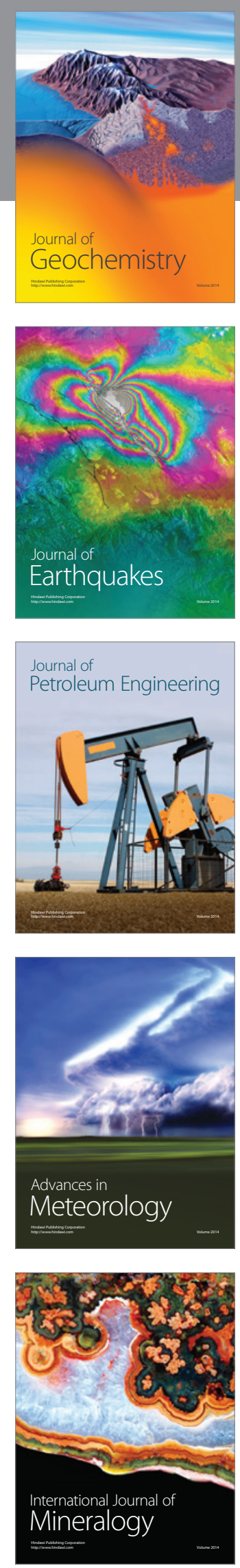
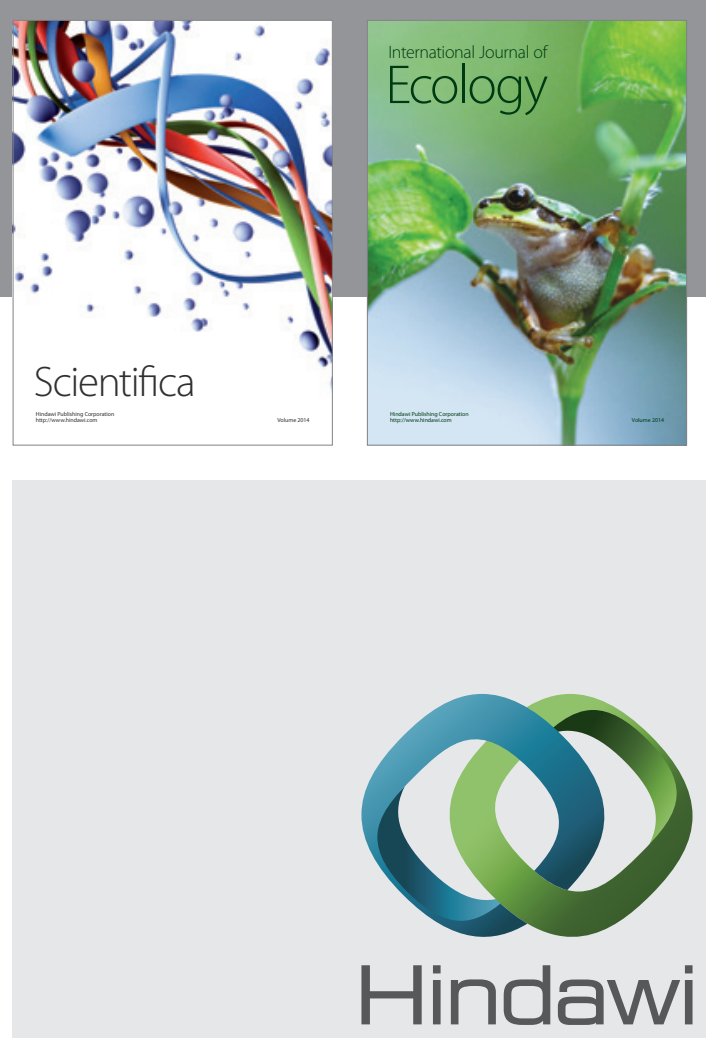

Submit your manuscripts at

http://www.hindawi.com
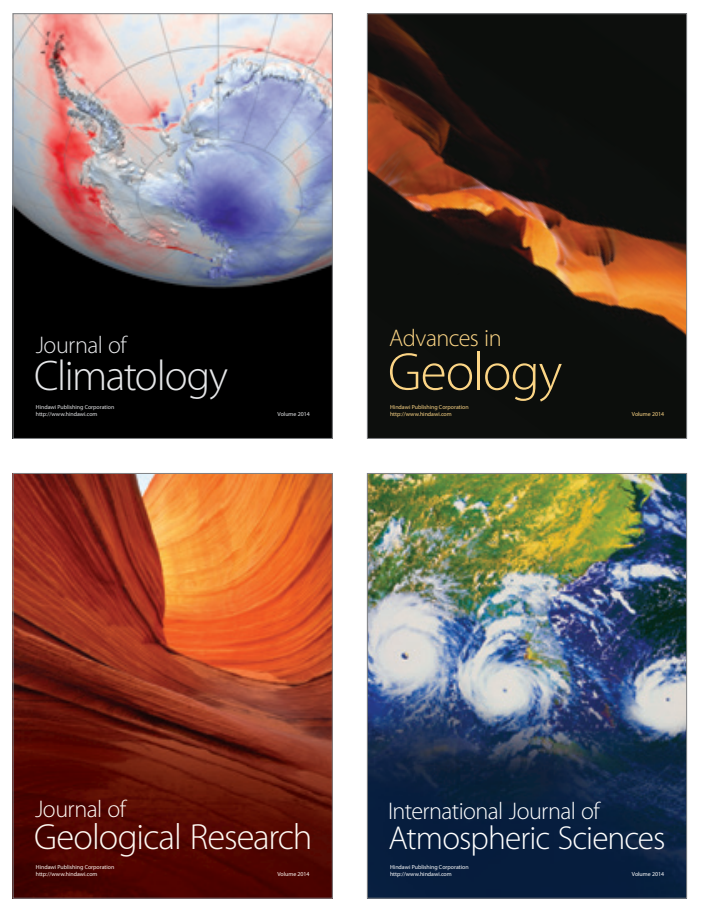

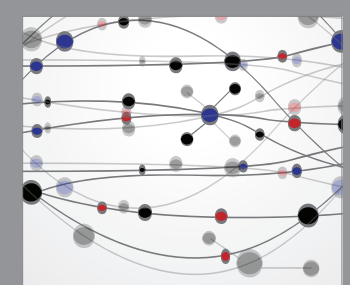

The Scientific

\section{World Journal}
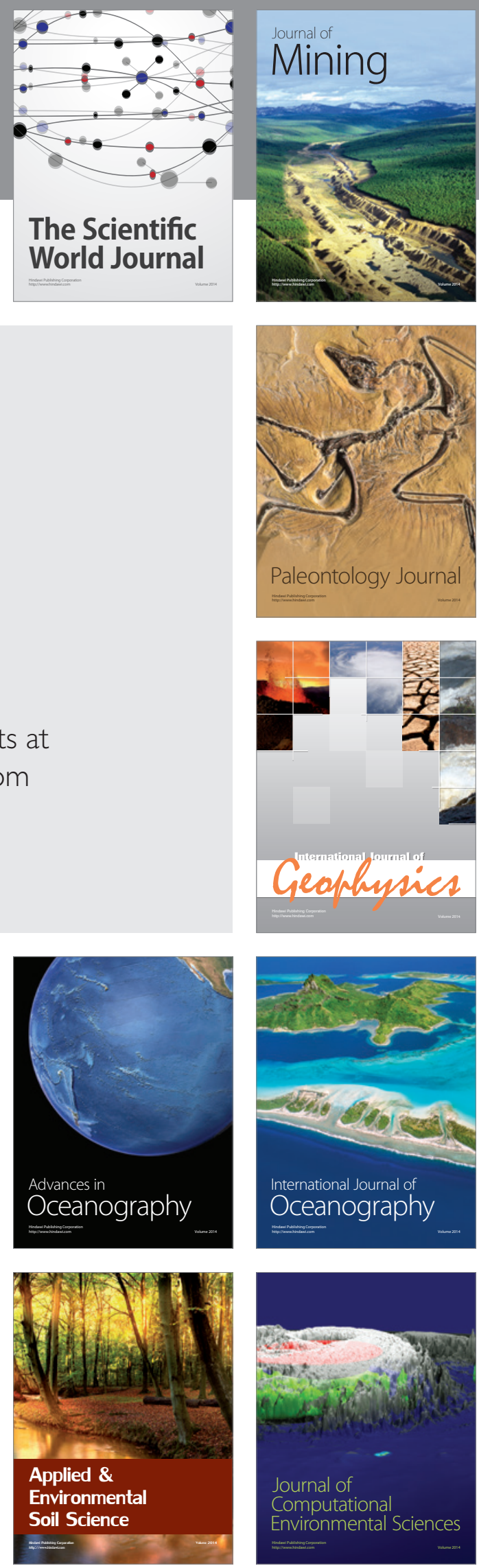